\title{
La Inmortalidad de nuestras Culturas Milenarias
}

Laura Marcela Zapata'

UniversidadNacionaldeJoséC.Paz,JoséC.Paz, ProvinciadeBuenosAires-Argentina

BERGAGNA, María Alejandra. La Inmortalidad de nuestras Culturas Milenarias. Salta: Comunidad Estudiantil Universitaria de Pueblos Originarios (CEUPO), 2013. 153 f. E-Book.

El estudio de los procesos culturales implicados en las prácticas educativas desarrolladas en situaciones de interacción interétnica se ha multiplicado en los últimos años. El encuentro interétnico en el ámbito escolar bien puede ser interpretado como la interacción de dos sistemas de comunicación, el indígena y el occidental, cuya mutua inteligibilidad demanda un esfuerzo meta-comunicativo. Aunque sea fundamental para que algún aprendizaje tenga lugar, buena parte del trabajo meta-comunicativo corre por las vías del lenguaje implícito. Por ello, pocas veces las instituciones educativas se comprometen en su explicitación reflexiva, máxime cuando la dominación étnica, precisamente, obtiene su eficacia de este y otros silenciamientos. La tematización del conjunto de reglas que ordenan la interacción y la interpretación, al interior de un proceso escolar, también llamada reflexividad, ofrece grandes oportunidades para conocer, desde el punto de vista de los actores sociales, la naturaleza y significado del orden social y las posibilidades para su transformación.

Educação \& Realidade, Porto Alegre, v. 40, n. 3, p. 949-954, jul./sept. 2015. 949 http://dx.doi.org/10.1590/2175-623651489 
El texto La inmortalidad de nuestras culturas milenarias retrata de manera sensible y certera una experiencia educativa de carácter reflexivo, orientada a explicitar, desde el punto de vista de los docentes no indígenas y de un grupo de estudiantes indígenas, los pactos simbólicos que organizaban el proceso de aprendizaje en el ámbito universitario, que llevaban a los estudiantes al fracaso académico y a la deserción. Se trata de un pequeño pero sugestivo libro digital aparecido el año 2013 en la provincia de Salta, noroeste argentino, editado por la Comunidad Estudiantil Universitaria de Pueblos Originarios (CEUPO) de la Universidad Nacional de Salta (UNSa), y compilado por la trabajadora social, profesora de la UNSa y coordinadora del Servicio de Orientación y Tutoría de la Facultad de Ciencias de la Salud, María Alejandra Bergagna.

Dos grandes bloques organizan el texto. Mientras que Bergagna, Verónica Vila, psicóloga perteneciente al Servicio de Orientación, y Juan M. Díaz Pas, un estudiante avanzado de la carrera de Letras de la UNSa, escriben una amplia introducción, "Escritores originarios: la apropiación de la voz", catorce estudiantes indígenas son los autores de la segunda parte del libro. Ellos son: Osvaldo 'Chiqui' Villagra, Ervis Díaz, A.C. Cielo, Sol, Emanuel Tapia, Marcos, Lidia, Magy, Vilma, Graciela, Rix, Robustiano Ramos, Amílcar y Anahí. Sus lugares de origen se hallan entre el Chaco Salteño-Jujeño (adonde residen grupos guaraníes y wikyi) y la Puna Jujeña (habitada, entre otros, por grupos kolla).

En la primera parte los autores describen el servicio de tutoría por el cual un grupo de estudiantes universitarios avanzados no indígenas acompañó, durante los años 2012 y 2013, a un grupo de estudiantes indígenas en su aclimatamiento institucional. A través de la organización de un Taller de Comprensión y Producción de Textos - del que participaron cinco tutores/as, estudiantes universitarios avanzados, no indígenas - se propusieron aproximar el lenguaje científico y académico a los estudiantes originarios, con objeto de facilitar su comprensión. En el transcurso del taller tutores/as y coordinadores/as hicieron varios descubrimientos. Primero, que los lazos entre la escritura y el poder se expresaban en las dificultades que tenían los estudiantes para comprender el discurso académico. Segundo, que esa incomprensión era el fruto de una “[...] estrategia de exclusión social más o menos evidente, más o menos formulada como proyecto” (Bergagna, 2013, p. 27). Tercero, y quizá el hallazgo más significativo, que

$$
\begin{aligned}
& \text { [...] no basta con enseñar a 'comprender' (es decir a leer, a } \\
& \text { consumir) los sentidos elaborados por otros, es necesario } \\
& \text { colaborar para que todos o muchos más accedan a 'pro- } \\
& \text { ducir' esos sentidos, a formularlos con su propia voz, en } \\
& \text { sus propios términos, según su propio ritmo, con el estilo } \\
& \text { de una lengua que los identifique con aquello que dicen } \\
& \text { (Bergagna, 2013, p. 28-29). }
\end{aligned}
$$

Los coordinadores, impulsados por los estudiantes indígenas, abandonaron el lenguaje científico como objeto. Se concentraron en la 
"escritura creativa"; eludieron las nociones de "aprobado/ desaprobado" para calificar la escritura de los estudiantes y en su lugar trabajaron con los conceptos de "edición" reflexiva: “[...] elaboración de estrategias de adecuación discursiva al contexto de participación, a los objetivos perseguidos por los participantes, a las representaciones mentales de los eventos de escritura y a las intenciones puestas en juego" (Bergagna, 2013, p. 33-34). De ello derivaron algunos de los tópicos sobre los que versó la escritura de los estudiantes: “[...] qué es ser kolla, qué es ser wicky [sic] o guaraní en la universidad nacional de Salta a principios del siglo XXI" (Bergagna, 2013, p. 36). Veamos entonces cómo respondieron a esta pregunta en la segunda parte del libro los autores wikyi, guaraní y kolla.

Además de una entrevista realizada por estudiantes secundarios de la ciudad de Salta a Osvaldo 'Chiqui' Villagra, predominan en la segunda parte del libro textos autobiográficos que se intercalan junto a relatos tradicionales (que describen el coquena, el origen del maíz, el origen del río Pilcomayo, las luciérnagas, entre otros). La lengua que usan los estudiantes para escribir es el español, aunque algunos textos (relatos tradicionales) son traducidos de manera simultánea a sus lenguas maternas, wikyi y guaraní. La mayoría de los autores firman sus textos recurriendo a sus nombres de pila (Celeste, Amílcar) o, aun, a sus sobrenombres (Magy, Rix), como si la comunidad de sus lectores pudiera reconocerlos, como lo hacen sus parientes y vecinos, a través de estas señales que emergen en el seno de la interacción cara a cara.

Consideradas en conjunto las autobiografías muestran lo inconmensurables que resultan los sistemas de aprendizaje propios de las culturas de los pueblos de los que provienen los estudiantes universitarios con respecto a la enseñanza escolar y universitaria. Veamos cómo producen estos autores esa ininteligibilidad en la que se halla comprometida su propia sobrevivencia en el ámbito universitario. Osvaldo Villagra, estudiante avanzado del Profesorado en Ciencias de la Educación de la UNSa, perteneciente al pueblo wikyi de la comunidad La Puntana, ubicada en el departamento de Rivadavia, Provincia de Salta, explica cómo aprendió a nadar y a pescar:

\begin{abstract}
Uno de mis grandes desafíos cuando tenía apenas 6 años de edad era aprender a nadar, junto con otros chicos de la comunidad lo hacíamos en 'pelhat'ilis' que en español sería lagunas - aguas estancadas dejadas por las lluvias o el río -, y siempre con la presencia de una persona mayor, como primera regla; aprender a nadar a la perfección y luego sumergirse dentro del agua sin abrir los ojos ya que el agua es turbia, solo hay que guiarse con las manos y brazos. Antes de ir al río tenía que recibir una aprobación para poder hacer la otra parte más difícil, la de nadar en el río, y conocer los secretos del agua, es decir, reconocer su movimiento para detectar las partes profundas y menos profundas, así poder atravesarla hasta el otro lado, cru-
\end{abstract}


zar y nadar por la noche. Todo esto es para luego no tener tanta dificultad a la hora de aprender a pescar (Bergagna, 2013, p. 48).

De esta explicación entendemos varias cosas sobre el sistema de enseñanza-aprendizaje local. Primero, los aprendices de la cultura wikyi son entrenados en los mismos contextos donde desempeñarán sus funciones una vez que hayan adquirido la pericia necesaria para ejecutarlas. Se trata de un conocimiento total que incluye una compleja teoría sobre el entorno y una delicada práctica, indisociables. Segundo, la división del trabajo del grupo (que separa a hombres de mujeres y niño/ as de adultos/as) garantiza que todo miembro pleno de la comunidad acceda a los conocimientos mínimos que garanticen su sobrevivencia. El acceso a ese conocimiento no es objeto de monopolio de una elite que se lo reserve para sí como medio de dominación. Tercero, la función instrumental del aprendizaje (aprender a nadar para aprender a pesar y saciar una necesidad vital) no se haya disociada del valor lúdico y recreativo del entrenamiento, que se presenta ante el niño como un "gran desafío".

Los autores originarios no oponen de manera tajante el sistema nativo de aprendizaje - holista y comprensivo - con respecto al sistema escolar occidental - abstracto, violento y compartimentalizado. La jerarquía, más o menos elaborada, está presente en todas las experiencias, nativas y escolares. Se trata más bien de la significatividad asociada a los nuevos saberes, a eso que Jean Lave denomina "aprendizaje como participación en comunidades de práctica” que se hacen inteligibles al sujeto, le dan un lugar en el mundo, transformando al mundo y él/ella en un solo movimiento.

Lidia, por ejemplo, cuenta cómo la emocionaba leer poesías en los actos escolares, a los que su madre asistía orgullosa, y que antes de los diez años comenzó, incluso, a escribir un libro sobre su vida (Bergagna, 2013, p. 121); Graciela, con ayuda de su familia, desde muy pequeña "leía todo lo que tenía a [...] [su] alcance” (Bergagna, 2013, p. 127); y, Amílcar antes de ir a jardín de infantes aprendió junto a su abuela a leer el cartel que estaba frente a su casa, que decía en letras grandes "Municipalidad de Santa Victoria Oeste” y en letras chicas: "Por un futuro mejor". Según estos autores, leer o escribir surgía del esfuerzo que hacían para ganarse un lugar digno al interior de un mundo en el que su presencia era requerida, deseada y reclamada.

Esta no es la experiencia de la mayoría de los escritores que aquí reseñamos. Muchos de ellos asocian el aprendizaje de la lecto-escritura con el "aprendizaje de la letra" y a este con el dolor de cabeza, el aburrimiento, la limitación de las horas de juego junto a los pares para hacer la "bendita tarea", a situaciones de humillación colectiva, a través de los ejercicios de lectura en voz alta en el aula o en la casa frente a los compañeros, parientes y amigos, y a ejercicios que demandan como condición 
la soledad, el aislamiento del grupo de amigos o de la dinámica familiar. La posibilidad legítima de ser objeto de castigos y de desaprobación pública, a través de órdenes impartidas con gritos, por parte de maestros/ as y familiares adultos, para muchos de los estudiantes está en íntima relación con los libros y las bibliotecas. Por ejemplo, Vilma señala en su texto: "De a poco empecé a leer pero nunca me sentía contenta con lo que leía porque me sentía incapaz de leer como mi maestra. Pero igual no me ponía a practicar, porque decía: ¿de qué me sirve leer?, es como que estaba confundida todo el tiempo” (Bergagna, 2013, p. 125).

Relatos auto-biográficos de estas características son los que predominan en la segunda parte del libro. Los textos son el resultado parcial de lo que sucedió con el Taller que organizó el Servicio de Orientación y Tutorías de la UNSa. En la primera parte Bergagna cuenta que durante los primeros encuentros los estudiantes manifestaban desinterés por el discurso científico que les era presentado como objeto de trabajo. La letra críptica aparecía como la representante de un mundo que denegaba persistentemente su presencia efectiva, como miembros de pueblos originarios, en la Universidad. Los desconocía como agentes capaces de producir significado en los términos de una voz, ritmo y estilo propios. Ante este desinterés por parte de los estudiantes originarios los coordinadores modificaron los términos en que era pensado el taller y abandonaron la "enseñanza magistral", dicen haberse concentrado en la "escucha” (Bergagna, 2013, p. 37).

De ello emergieron varias iniciativas por parte de los estudiantes. Organizaron una feria universitaria donde mostrar sus ropas, bailes, canciones y productos que fabricaban con sus manos. Comenzaron a dictar cursos de idioma y cultura wikyi en la escuela secundaria que dependía de la UNSa. Finalmente, organizaron el CEUPO que le dio una representación política en el ámbito universitario. Escribir sobre los derroteros, muchos veces violentos, a través de los cuales estos estudiantes habían llegado a la universidad, transformó al taller y el propio concepto de escritura. Usada como performance junto a otras actividades expresivas, apareció como un instrumento a través del cual modificar los términos en los cuales la exclusión y la denegación eran incluidas como principios implícitos de interacción y base de la enseñanza-aprendizaje en el ámbito universitario.

La enseñanza universitaria simplemente ignoraba a quiénes tenía frente a sí, los saberes que portaban y sus culturas de origen, considerándolos simples receptores pasivos de un conocimiento magistral. Se trata de un principio que pocos estudiantes (indígenas o no indígenas) logran problematizar. Este grupo lo hizo sosteniendo que sus culturas de origen eran "milenarias" e "inmortales". El título del libro, una afirmación existencial y política, presenta la intención de este grupo de estudiantes: que la institución reconociera su origen étnico como propiedad y principio ineludible para su existencia efectiva en el medio universitario.

Educação \& Realidade, Porto Alegre, v. 40, n. 3, p. 949-954, jul./sept. 2015. 953 
Si la transmisión de la cultura supone una teoría acerca de cómo es producido y reproducido el conocimiento por parte de los miembros de un grupo social, es decir, si entendemos a la cultura como un lugar adonde se elaboran epistemologías, entonces hay en los escritos de los autores indígenas de este libro un esfuerzo por mostrar sus propias maneras de aprender y enseñar diversas dimensiones de su cultura y de su entorno. Comprendemos, de la mano de los estudiantes, que en nuestras Universidades conviven diversas epistemologías. Reconocerlas, como condición de nuevos aprendizajes, es un primer paso, y en esta línea se halla el libro que reseñamos. El segundo paso es el diálogo, en igualdad de condiciones, de diversas epistemologías que conviven, de hecho, en el ámbito universitario. Esto es una materia pendiente para la enseñanza universitaria y para la investigación. Como sostiene Alcida Rita Ramos, para el caso de la Antropología Social, las teorías nativas acerca del saber y las teorías académicas podrían no sólo dialogar sino, incluso, fertilizarse mutuamente, colaborando en la institución de una verdadera "ecumene teórica”, una congregación de teorías sociales. Ello transformaría, enriqueciendo, nuestra manera (homogénea y autoritaria) de producir conocimientos.

"La inmortalidad de nuestras culturas milenarias" es fruto del proyecto "Interculturalidad e inclusión en contextos regionales. Un análisis de las dimensiones vinculadas al ingreso a la universidad en estudiantes indígenas", que fue desarrollado en la UNSa con el apoyo de la Secretaría de Política Universitaria del Ministerio de Educación del estado nacional argentino. Escrito a partir del método "Sistematización de Experiencias", se trata de un esfuerzo intelectual por mostrar los desafíos culturales y políticos comprometidos en las prácticas educativas cuando son desarrolladas en situaciones de interacción interétnicas. De ello surge el valor por comentar su aparición y promover su lectura.

Recibido en 11 de noviembre 2014 Aprobado en 09 de abril 2015

\section{Referencia}

BERGAGNA, María Alejandra. La Inmortalidad de nuestras Culturas Milenarias. Salta: Comunidad Estudiantil Universitaria de Pueblos Originarios (CEUPO), 2013. 153 p. E-Book.

Laura Marcela Zapata es antropóloga social. Investigadora adscripta al Centro de Antropología Social, Instituto de Desarrollo Económico y Social. Profesora del Departamento de Ciencias Sociales de la Universidad Nacional de José C. Paz.

E-mail: lauramarcelazapata@yahoo.com.ar 